\title{
Estabilidade térmica da zeólita A sintetizada a partir de um rejeito de caulim da Amazônia
}

\section{(Thermal stability of the zeolite A synthesized after kaolin waste from Amazon region)}

\author{
A.A.B.Maia ${ }^{1}$, R.S.Angélica ${ }^{2}$, R.F.Neves ${ }^{1}$ \\ ${ }^{1}$ Programa de Pós-Graduação em Engenharia Química, Universidade Federal do Pará \\ ${ }^{2}$ Instituto de Geociências, Universidade Federal do Pará \\ anabmaia@yahoo.com.br
}

\begin{abstract}
Resumo
Zeólita A foi calcinada nas temperaturas de $200,400,600,800$ e $1000{ }^{\circ} \mathrm{C} / 2 \mathrm{~h}$ para estudar sua estabilidade térmica. A síntese foi feita a partir de um rejeito de beneficiamento de caulim para a produção de papel de uma empresa mineradora localizada na região Amazônica. A caracterização da zeólita A calcinada nas diferentes temperaturas foi realizada por difração de raios X e microscopia eletrônica de varredura. A zeólita A permaneceu estável até $600{ }^{\circ} \mathrm{C}$, havendo apenas variações nas intensidades dos picos em função da temperatura. A $800{ }^{\circ} \mathrm{C}$ o padrão de difração apresentado pelo material continuava sendo da zeólita A mas com ausência de alguns picos. A $1000{ }^{\circ} \mathrm{C}$ foi constatado que o produto de calcinação era constituído de nefelina, mulita e provavelmente sodalita. Essa zeólita também foi aquecida em mais duas temperaturas, 900 e $950^{\circ} \mathrm{C}$, com o objetivo de confirmar os dois picos exotérmicos observados em curva de análise térmica diferencial. Os produtos de calcinação nessas temperaturas eram constituídos de nefelina, sodalita e mulita.

Palavras-chave: rejeito de caulim, zeólita A, estabilidade térmica.
\end{abstract}

\begin{abstract}
Zeolite A was calcined at 200,400,600, 800 and $1000{ }^{\circ} \mathrm{C}$ for $2 \mathrm{~h}$ to evaluate its thermal stability. The zeolite A was synthesized using kaolin waste from kaolin processing industries for paper coating located in the Amazon region. Both zeolite A and further calcined products were characterized by X-ray diffraction analysis and scanning electron microscopy. The zeolite A structure remained stable up to $600{ }^{\circ} \mathrm{C}$, where only small variations in peak intensities were observed. At $800{ }^{\circ} \mathrm{C}$ the diffraction pattern still exhibited zeolite A but with the absence of some peaks. At $1000^{\circ} \mathrm{C}$ nepheline, mullite and probably sodalite were formed. The zeolite A was also heated at 900 and $950^{\circ} \mathrm{C}$ to check the two exothermic peaks observed in the DTA curve. The X-ray diffraction analysis indicated the presence of nepheline, sodalite and mullite.

Keywords: kaolin waste, zeolite A, thermal stability.
\end{abstract}

\section{INTRODUÇÃO}

Apesar do setor mineral, e de modo especial, o beneficiamento de caulim ter uma grande importância sócioeconômica para o estado do Pará, esse tipo de atividade pode gerar uma perda na qualidade ambiental. Como em todos os processos de beneficiamento, a utilização de caulim para cobertura de papel passa por tratamentos físicos e químicos, que geram dois tipos de rejeitos principais: o primeiro é basicamente constituído de quartzo, correspondendo a cerca de $10 \%$ da produção bruta; e o outro, em torno de $26 \%$, é constituído principalmente por caulinita, sendo esse armazenado em grandes lagoas de sedimentação. Esse resíduo possibilita, dessa maneira, a produção de uma metacaulinita extremamente reativa. Vale ressaltar que esse material é considerado como rejeito devido a sua granulometria $(>2 \mu \mathrm{m})$ que é inadequada para a indústria de cobertura de papel. Em relação às normas da ABNTNBR [1], o mesmo pode ser classificado como não perigoso por ser gerado a partir de um mineral não-metálico. Dessa forma, esse rejeito vem sendo utilizado como matériaprima pelo Grupo de Mineralogia e Geoquímica Aplicada da Universidade Federal do Pará para o desenvolvimento de diversos trabalhos, entre eles a síntese de zeólitas [3].

Zeólitas são aluminossilicatos hidratados cristalinos de metais e metais alcalinos terrosos [4]. Sua estrutura, formada por poros de dimensão moleculares, revela um arranjo regular de canais e cavidades (3-15 $⿱$ ), criando assim um labirinto em escala nanométrica que pode ser preenchido por moléculas de água ou outras [5].

A zeólita A é uma típica zeólita sintética usada freqüentemente nas indústrias de petróleo e química como catalisador, trocador de íon ou peneira molecular. Atualmente tem chamado atenção pela sua utilização como 
membrana para separar $\mathrm{H}_{2}, \mathrm{H}_{2} \mathrm{O}$ e outras moléculas pequenas de misturas de gases ou líquidos [6]. Normalmente a zeólita A é sintetizada na forma sódica. Outra forma catiônica pode ser facilmente preparada por troca iônica em solução aquosa [7]. Possui morfologia cúbica bem característica e tem uma razão Si/Al mínima em relação a outras zeólitas [8]. Em relação à temperatura ideal de síntese da zeólita $\mathrm{A}$, a partir de metacaulinita, acreditava-se que ocorreria entre 70 a 100 ${ }^{\circ} \mathrm{C}[4,9,10]$. No entanto, foi verificado que essa zeólita pode ser cristalizada em temperaturas fora dessa faixa, como por exemplo a $60{ }^{\circ} \mathrm{C}$, em que a caulinita passou por um tratamento mecânico e a síntese foi realizada através de um sistema de agitação [11]. Outro exemplo é o trabalho em que primeiramente a caulinita foi calcinada para obtenção da metacaulinita, ocorrendo após a síntese em condições hidrotermais a $105^{\circ} \mathrm{C}$, em que se variou a disponibilidade de sódio no meio reacional para que fosse estudada a sua influência [11]. Já os autores do presente trabalho utilizaram a temperatura de $110^{\circ} \mathrm{C}$, a partir de metacaulinita, proveniente de um rejeito, sendo a zeólita A sintetizada em autoclave [3]. Dessa maneira, a síntese da zeólita A não depende somente da temperatura, mas também de como foi realizada a síntese (com ou sem agitação), da disponibilidade de sódio no meio reacional, do tipo de caulinita utilizada como material precursor e do tipo do tratamento dado a caulinita para a obtenção da metacaulinita. No processo de síntese são vários os fatores que influenciam nas propriedades características das zeólitas, desde o material de partida, fontes de alumínio, silício e cátions, até as condições do processo como temperatura, pressão, concentração, tempo e pH. Entretanto, mesmo após a síntese, é possível realizar um tratamento nas zeólitas, alterando-se sua composição química e, conseqüentemente, suas propriedades [13]. Entre os principais processos citam-se, entre outros, os tratamentos térmicos e hidrotérmicos [14], troca iônica [15] e a extração de alumínio [16].

No estudo da estabilidade térmica da zeólita A de sódio, foi observado que a $1000{ }^{\circ} \mathrm{C}$ o produto de calcinação era composto por uma mistura contendo $50 \%$ de carnegieita e nefelina, sendo que anteriormente houve a formação de um composto aluminosilicato amorfo [17]. Prolongando-se o tempo de aquecimento, foi observada a transformação da carnegieita em nefelina. Nesse mesmo trabalho foi estudada também a estabilidade térmica de outras zeólitas e assim como no caso da zeólita A de sódio, foi observada a formação de uma fase amorfa na primeira etapa da reação.

Dessa forma, o estudo do tratamento térmico das zeólitas tem ganhado muita importância pelo fato de alguns desses materiais apresentarem grande eficiência como catalisadores para altas temperaturas [18]. Da mesma forma, através da transformação térmica das zeólitas é possível a produção de aluminosilicatos fundamentais na indústria cerâmica [19]. Isso mostra que embora algumas zeólitas não apresentem estabilidade térmica apreciável, como é o caso daquelas de baixa relação $\mathrm{Si} / \mathrm{Al}$ [20,21], ainda assim é necessário fazer um estudo do seu comportamento em altas temperaturas para que seja verificada sua transformação de fases. Com isso, o objetivo desse trabalho foi realizar um estudo da estabilidade térmica da zeólita A, sintetizada a partir do rejeito de caulim [3], por meio de técnicas de difração de raios X e microscopia eletrônica de varredura, para que fossem avaliadas as possíveis modificações na sua estrutura em função da variação da temperatura.

\section{MATERIAIS E MÉTODOS}

Como fonte de silício e alumínio foi utilizado um rejeito de beneficiamento de caulim oriundo de uma indústria de mineração instalada na região amazônica. A fonte de metal alcalino usado na síntese foi hidróxido de sódio (Casa da Química).A mistura reacional utilizada na síntese apresentou a composição molar $1,26 \mathrm{Na}_{2} \mathrm{O} \cdot \mathrm{Al}_{2} \mathrm{O}_{3} \cdot 2 \mathrm{SiO}_{2} \cdot \mathrm{nH}_{2} \mathrm{O}$ [22].

A síntese da zeólita A passou por duas etapas. A primeira consistiu na ativação térmica do resíduo de caulim, submetido a calcinação a $700{ }^{\circ} \mathrm{C}$ por $2 \mathrm{~h}$ para que toda caulinita se transformasse em metacaulinita. $\mathrm{Na}$ segunda etapa o hidróxido de sódio em solução $5 \mathrm{~N}$ foi adicionado a metacaulinita a $110{ }^{\circ} \mathrm{C}$ por $24 \mathrm{~h}$ em condições hidrotermais através de autoclavagem estática [3]. Os materiais de partida e os sintetizados foram analisados por difração de raios $\mathrm{X}$ (DRX) e microscopia eletrônica de varredura (MEV).

Cerca de 2 g da zeólita A foram pesadas em balança analítica e colocadas em cadinho de porcelana para tratamento térmico a $200{ }^{\circ} \mathrm{C}$ por $2 \mathrm{~h}$. Os ensaios foram repetidos, da mesma forma, para $400{ }^{\circ} \mathrm{C}, 600{ }^{\circ} \mathrm{C}, 800{ }^{\circ} \mathrm{C}$ e $1000{ }^{\circ} \mathrm{C}$. Posteriormente os cadinhos foram retirados da mufla $\mathrm{e}$ levados ao dessecador até equilíbrio térmico na temperatura ambiente. Estes materiais foram caracterizados por DRX e MEV. A zeólita A também foi aquecida a $900{ }^{\circ} \mathrm{C}$ e $950{ }^{\circ} \mathrm{C}$, em que ocorrem picos exotérmicos [3]. O procedimento para essa calcinação foi o mesmo descrito anteriormente.

A caracterização do material de partida, da zeólita A e da mesma calcinada nas diferentes temperaturas do processo foi feita por DRX e MEV. Todas essas técnicas foram descritas [3]. A composição química do rejeito de caulim [2] foi verificada através de diferentes métodos para determinação dos teores dos seguintes óxidos: $\mathrm{SiO}_{2}$ e perda ao fogo por gravimetria (método clássico); $\mathrm{Al}_{2} \mathrm{O}_{3}$ por titrimetria (método clássico); $\mathrm{Fe}_{2} \mathrm{O}_{3}$ e $\mathrm{TiO}_{2}$ por espectrofotometria (método colorimétrico), $\mathrm{Na}_{2} \mathrm{O}, \mathrm{K}_{2} \mathrm{O}, \mathrm{CaO}, \mathrm{MgO}$ por espectrometria de absorção atômica.

\section{RESULTADOS E DISCUSSÃO}

Na Fig. 1 são apresentados os difratogramas de raios $\mathrm{X}$ do rejeito de caulim in natura, do rejeito de caulim calcinado e da zeólita A sintetizada. O rejeito de caulim utilizado como fonte de Si e Al é constituído principalmente pelo argilomineral caulinita, com os seus dois picos principais em $7,15 \AA$ (001) e 3,56 $\AA$ (002). O rejeito tratado termicamente foi transformado totalmente para metacaulinita, observado assim pelo completo rompimento de sua estrutura cristalina. $\mathrm{O}$ produto resultante da síntese constituiu-se essencialmente por zeólita A, sendo que sua formação nesta etapa ocorreu 


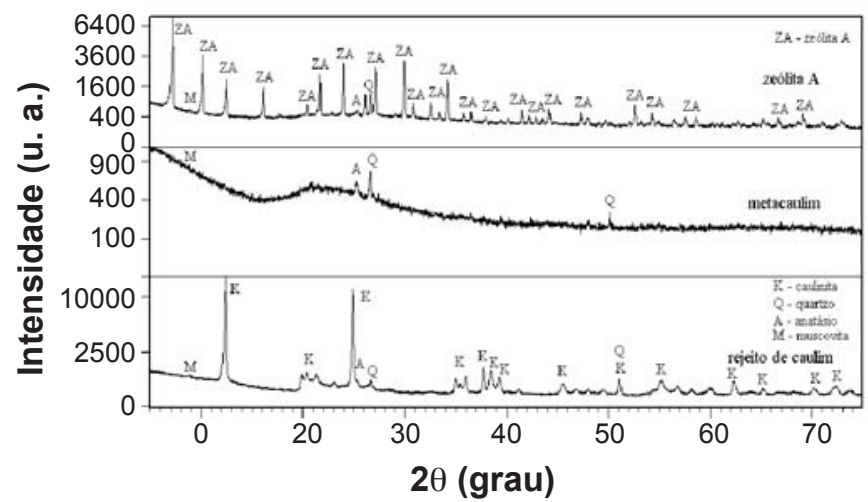

Figura 1: Difratogramas de raios $\mathrm{X}$ do processo de síntese da zeólita A.

[Figure 1: XRD patterns of the zeolite A synthesis process.]

com elevado grau de ordem estrutural, com padrão difratométrico representado por picos estreitos e bem delineados. Verificou-se a presença de impurezas como anatásio, muscovita e quartzo em pequenas quantidades em todos os difratogramas. Vale ressaltar que estes minerais, de um modo geral, estão sempre presentes nas ocorrências de caulim da região, são separados durante o processamento, porém depois são novamente lançados nas bacias de rejeito.

A morfologia das partículas do rejeito de caulim, do rejeito de caulim calcinado (metacaulinita) e da zeólita A está apresentada na Fig. 2. Constatou-se que a caulinita é formada por partículas micrométricas, de forma pseudo-hexagonal característica (Fig. 2a). A metacaulinita constituiu-se de partículas aglomeradas e a morfologia pseudo-hexagonal foi mantida (Fig. 2b). O material sintetizado apresentou cristais de morfologia cúbica característicos da zeólita A (Fig. 2c). Dessa forma, ao se comparar a morfologia da caulinita com a do produto sintetizado, observou-se uma mudança morfológica, na qual a forma inicial pseudo-hexagonal da caulinita passou a apresentar uma outra morfologia, a cúbica, indicando a cristalização da zeólita A.

Acomposição química do rejeito de caulim está apresentada na Tabela I. Nesta encontra-se também a composição de um caulim [23], e que ocorre na mina de uma das empresas da região, além da caulinita teórica, para efeito de comparação. Os valores dos teores de alumina, sílica e da perda ao fogo encontrados no rejeito de caulim são próximos aos da caulinita teórica, confirmando assim os dados de difração de raios $\mathrm{X}$ em que a caulinita foi o principal constituinte. Nos teores de sílica estão incluídos os da caulinita e do quartzo, que segundo dados de DRX se encontram em pequena quantidade. Dessa forma, os teores de sílica e alumina referentes à caulinita são a fonte necessária desses elementos para a produção de zeólitas. E no caso da zeólita A, objeto de estudo deste trabalho, em que a razão $\mathrm{SiO}_{2} / \mathrm{Al}_{2} \mathrm{O}_{3}$ é igual à da caulinita, houve somente a utilização do rejeito de caulim como fonte desses elementos. Valores para $\mathrm{Fe}_{2} \mathrm{O}_{3}$ e $\mathrm{TiO}_{2}$ apresentados pelo rejeito de caulim estão abaixo dos teores médios encontrados no caulim natural [23] devido ao material analisado (rejeito) já ter sido processado e passado, previamente, pelo separador magnético, que elimina
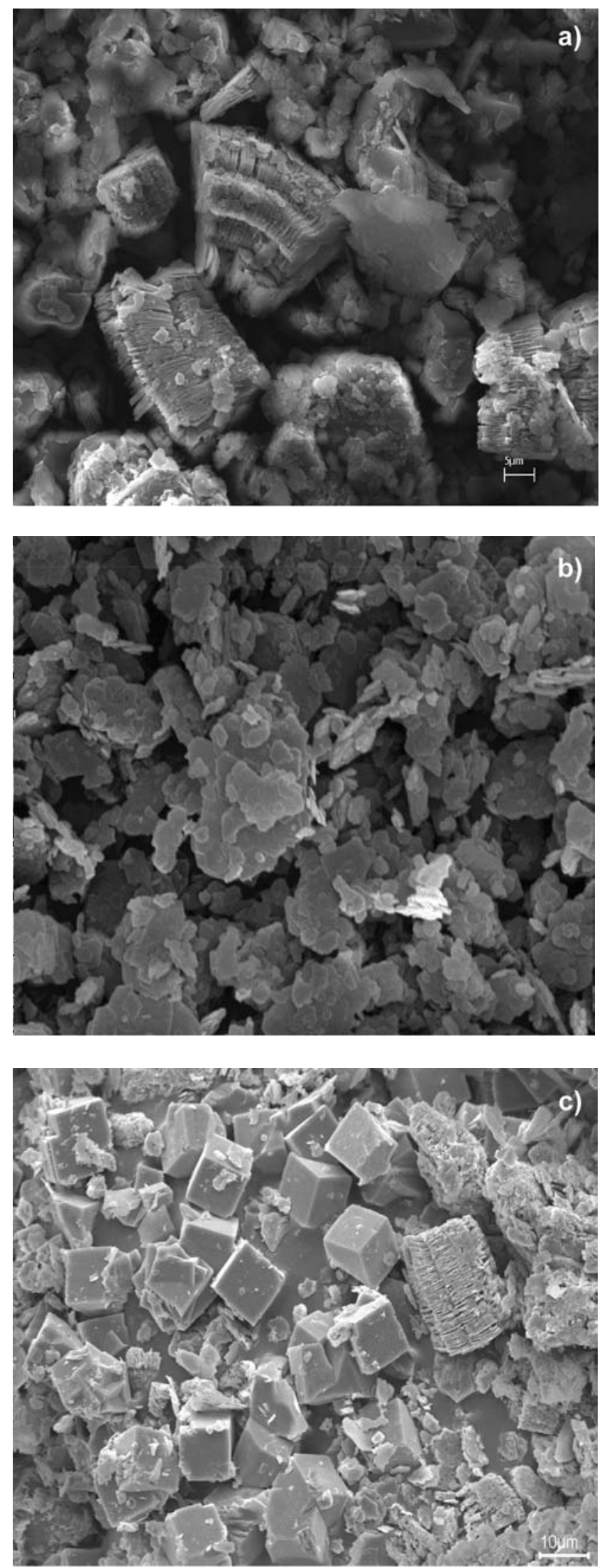

Figura 2: Morfologia do rejeito de caulim (a), da metacaulinita (b) e da zeólita A (c).

[Figure 2: Morphologies of the samples kaolin wastes (a), metakaolinite (b) and zeolite A (c).] 
Tabela I - Composição química do rejeito de caulim. [Table I - Chemical composition of waste kaolin.]

\begin{tabular}{cccc}
\hline \% óxidos & $\begin{array}{c}\text { Rejeito de } \\
\text { caulim }\end{array}$ & $\begin{array}{c}\text { Caulim da } \\
\text { região }^{22}\end{array}$ & $\begin{array}{c}\text { Caulinita } \\
\text { teórica }\end{array}$ \\
\hline $\mathrm{SiO}_{2}$ & 46,50 & 43,16 & 46,54 \\
$\mathrm{Al}_{2} \mathrm{O}_{3}$ & 38,40 & 39,03 & 39,50 \\
$\mathrm{Fe}_{2} \mathrm{O}_{3}$ & 0,69 & 1,29 & - \\
$\mathrm{TiO}_{2}$ & 0,96 & 1,26 & - \\
$\mathrm{CaO}$ & - & $<0,01$ & - \\
$\mathrm{MgO}$ & - & 0,01 & - \\
$\mathrm{Na}_{2} \mathrm{O}$ & - & 0,13 & - \\
$\mathrm{K}_{2} \mathrm{O}$ & 0,10 & 0,01 & - \\
$\mathrm{PF}$ & 13,60 & 14,41 & 13,96 \\
$\mathrm{Total}$ & 100,25 & 99,34 & 100 \\
\hline
\end{tabular}

${ }^{1}$ Martelli (2006), ${ }^{22}$ Carneiro (2002).

os minerais de Fe e Ti.

Os difratogramas da transformação térmica da zeólita A a 200, 400, 600 e $800{ }^{\circ} \mathrm{C}$ são apresentados na Fig. 3. Na Fig. 4 estão os difratogramas da zeólita A calcinada a 900, 950 e $1000{ }^{\circ} \mathrm{C}$. As morfologias da zeólita A calcinada a $800{ }^{\circ} \mathrm{C}$ e $1000{ }^{\circ} \mathrm{C}$ são apresentadas na Fig. 5 a-b.

Observa-se na Fig. 3 que em todas as temperaturas de calcinação (200 a $800{ }^{\circ} \mathrm{C}$ ), a zeólita A permaneceu como principal constituinte. Em $200{ }^{\circ} \mathrm{C}$ a estrutura dessa zeólita começa um processo de "desordenamento" com ligeira diminuição da intensidade e alargamento de seus picos. Em seguida, a 400 e $600{ }^{\circ} \mathrm{C}$, aparentemente, a estrutura

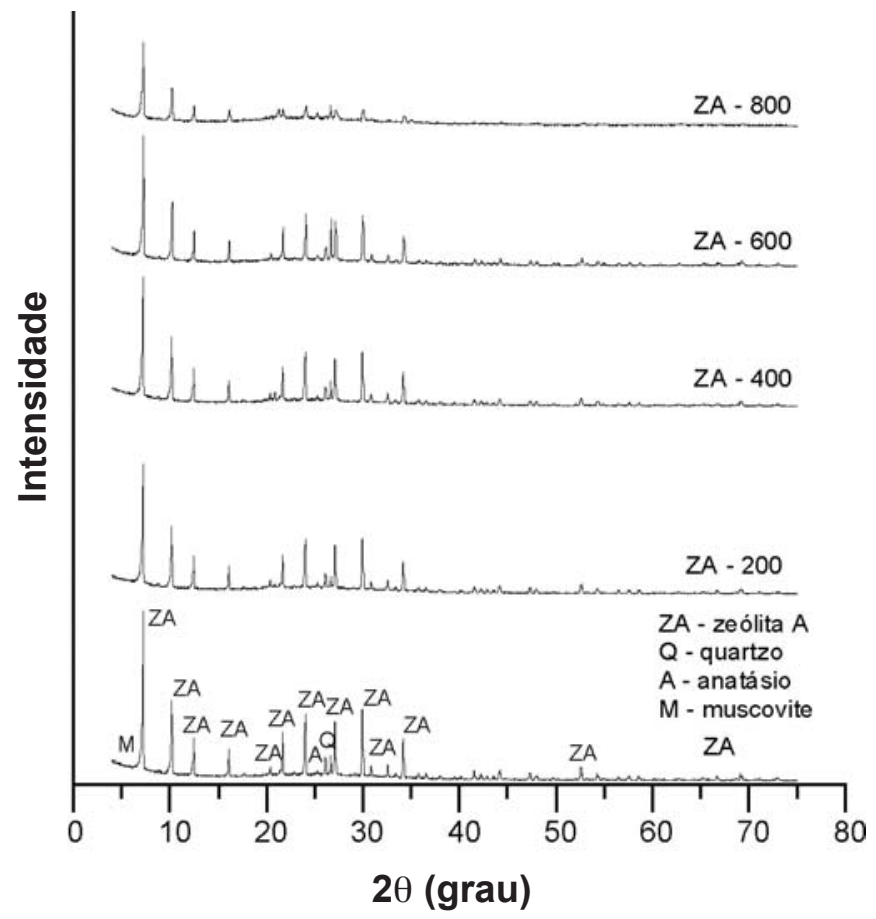

Figura 3: Difratogramas de raios $\mathrm{X}$ da zeólita A e da mesma calcinada a $200,400,600$ e $800{ }^{\circ} \mathrm{C}$.

[Figure 3: XRD patterns of the zeolite A and of the same calcined at $200,400,600$ and $800{ }^{\circ} \mathrm{C}$.]

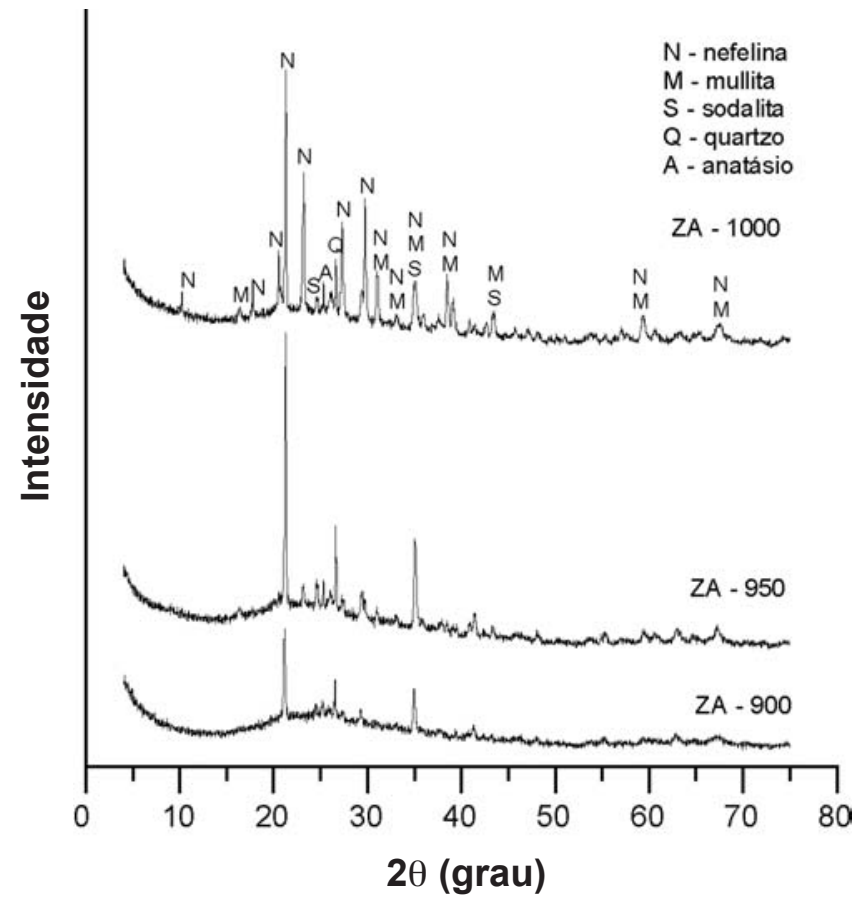

Figura 4: Difratogramas de raios $\mathrm{X}$ da zeólita $\mathrm{A}$ calcinada nas temperaturas de 900,950 e $1000{ }^{\circ} \mathrm{C}$.

[Figure 4: XRD patterns of the zeolite A sample and of the same calcined at 900,950 and $1000{ }^{\circ} \mathrm{C}$.]

volta a se ordenar, aumentando a intensidade de seus picos com o aumento da temperatura. A $800{ }^{\circ} \mathrm{C}$ a estrutura tende novamente a se desordenar, com nova diminuição na intensidade dos picos, além do desaparecimento de outros. É nítida a formação de quantidade significativa de material não cristalino (Fig. 3). Entretanto, a morfologia dos cristais permanece inalterada, como pode ser verificado na Fig. 5a. Portanto, o produto calcinado a $800{ }^{\circ} \mathrm{C}$ é constituído de cristais cúbicos e cristais de morfologia irregular, possivelmente material amorfo, já que a estrutura da zeólita A passou por um desordenamento.

Como pode ser verificado na Fig. 4 , a $1000^{\circ} \mathrm{C}$ o produto de calcinação passou por transformação de fases. Esse produto passou a ser constituído por nefelina, mullita e provavelmente sodalita, que apresentou picos de intensidades bem menores em relação aos outros minerais presentes. Acredita-se que nesta temperatura provavelmente houve a conversão da zeólita A para nefelina e sodalita. É importante mencionar que na mineralogia-geologia esses minerais, assim como a leucita, lazurita, cancrinita, dentre outros, são classificados como feldspadóites (feldspatos com baixo teor de $\mathrm{SiO}_{2}$ ) [24], enquanto que na Química ou Ciência dos Materiais os mesmos são considerados zeólitas. Kosanovic [17] também encontrou um resultado semelhante (nefelina e carnegieite), sendo que o outro feldspadóite nesse caso seria a carnegieita. Essa conversão ocorre diretamente [3] ou como resultado de recristalização $[17,18]$. A mulita formada provavelmente corresponde à transformação de fase da metacaulinita, utilizada como material precursor já que, segundo dados de 

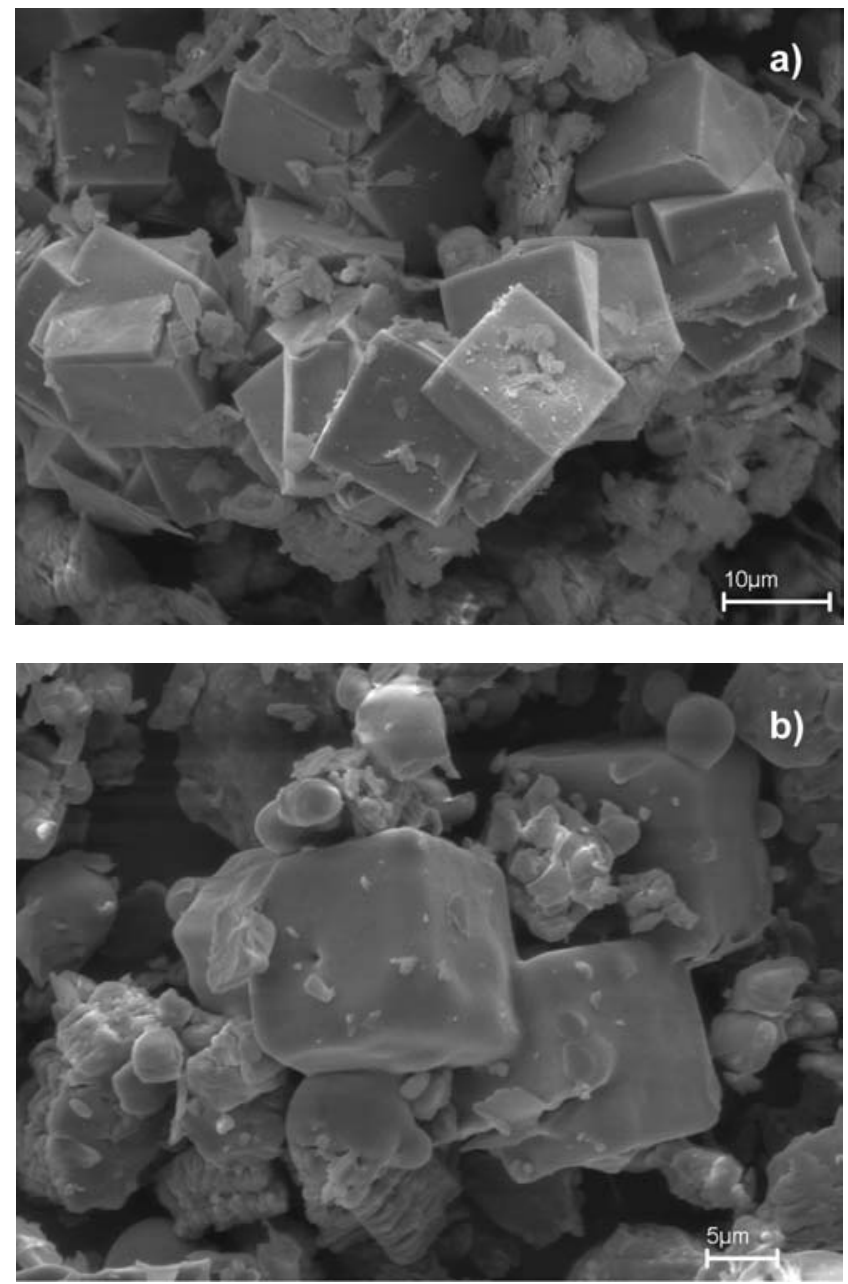

Figura 5: Morfologias da zeólita A calcinada nas temperaturas de $800{ }^{\circ} \mathrm{C}$ (a) e $1000{ }^{\circ} \mathrm{C}(\mathrm{b})$.

[Figure 5: Morphologies of the zeolite A samples calcined at $800{ }^{\circ} \mathrm{C}$ (a) and $1000{ }^{\circ} \mathrm{C}(\mathrm{b})$.]

DRX (Fig. 1), o produto de síntese é constituído por zeólita A e material não cristalino, possivelmente a metacaulinita.

O grau da ordem estrutural da caulinita é uma das variáveis que controlam a temperatura de mulitização, sendo que em torno de $1000{ }^{\circ} \mathrm{C}$ para elevada ordem e em torno de $1200{ }^{\circ} \mathrm{C}$ para baixa [25].

A análise morfológica do produto calcinado a $1000{ }^{\circ} \mathrm{C}$ (Fig. 5b) mostrou que esse processo provocou uma mudança na morfologia, que passou a ser na forma de cristais cúbicos com arestas arredondadas, dominantes, associados às massas irregulares, por vezes na forma de glóbulos ou sem formas definidas.

A 900 e $950{ }^{\circ} \mathrm{C}$ (Fig. 4) a nefelina se encontra como fase dominante, com picos mais intensos, enquanto a sodalita e a mullita mostraram-se presentes em pequenas quantidades, apresentando picos de menores intensidades. O acréscimo da temperatura de 900 para $1000{ }^{\circ} \mathrm{C}$ contribuiu para um aumento da ordem estrutural da nefelina, com nítida redução da largura a meia-altura (FWHM) dos picos $\left(0,20^{\circ}\right.$ em $2 \theta$ a $900{ }^{\circ} \mathrm{C}$ e $0,15^{\circ}$ em $2 \theta$ a $1000{ }^{\circ} \mathrm{C}$ ), além da diminuição dos picos principais da sodalita. Provavelmente houve conversão gradual da sodalita para nefelina, já que essa fase é a mais estável [17]. A carnegieita cúbica é formada pelo aquecimento da nefelina a temperaturas superiores a 1250 ${ }^{\circ} \mathrm{C}$ [26]. Da mesma forma, esse aumento na temperatura também favoreceu a formação de uma maior quantidade de mulita. Assim, em todas essas temperaturas de calcinação (900 a $1000{ }^{\circ} \mathrm{C}$ ) também foi observada uma quantidade significativa de material não cristalino, verificado pela significativa elevação no background nos difratogramas de raios X (Fig. 4).

\section{CONCLUSÕES}

A zeólita A não sofreu transformação de fase na faixa de 200 a $800{ }^{\circ} \mathrm{C}$. Nessas temperaturas ocorreu somente variação nas intensidades dos picos característicos, sendo que a $800{ }^{\circ} \mathrm{C}$, além dessa observação, verificou-se também desaparecimento de alguns picos, provavelmente devido à desordem de sua estrutura cristalina. A $1000{ }^{\circ} \mathrm{C}$ observouse a formação de nefelina e provavelmente sodalita, a partir da zeólita A, assim como a possível formação de mulita a partir da metacaulinita pré-existente. A 900 e $950{ }^{\circ} \mathrm{C}$ o produto de síntese constituído principalmente por zeólita A passa por transformação de fases, tendo como resultado apenas a presença da nefelina, sodalita e mulita. De forma que a transformação de fase iniciou a $900{ }^{\circ} \mathrm{C}$, e a $1000{ }^{\circ} \mathrm{C}$ o produto de calcinação apresentou a mesma constituição, porém foi observado um aumento na ordem estrutural para nefelina e mullita.

O rejeito de beneficiamento de caulim para papel mostrouse como uma excelente matéria-prima para produção de zeólita A pura [3], sendo dessa forma mais uma alternativa na tentativa de minimizar impactos ambientais. Outros estudos já vêm confirmando essas e outras possibilidades de aproveitamento desses rejeitos [2, 27-29].

\section{AGRADECIMENTOS}

Ao Conselho Nacional de Desenvolvimento Científico e Tecnológico - CNPq pelo apoio financeiro ao projeto "Aplicação de resíduos de caulim da região Amazônica para a produção de refratários e utilização em fornos na indústria de cerâmica vermelha", Edital Universal 19/2004, Proc. 472.252/2004-6, além da bolsa de produtividade em pesquisa (R. S. Angélica, processo 300.720/2004-1).

\section{REFERÊNCIAS}

[1] ABNT - Associação Brasileira de Normas Técnicas, Amostragem de Resíduos, NBR-10004, Rio de Janeiro (2004).

[2] M. C. Martelli, “Transformações térmicas e propriedades cerâmicas de resíduos de caulins das regiões do Rio Capim e do Rio Jarí- Brasil", Tese de Doutorado em Geoquímica e Petrologia, Universidade Federal do Pará, Belém, PA (2006). 
[3] A. A. B. Maia, E. Saldanha, R. S. Angélica, C. A. G. Souza, R. F. Neves, Cerâmica 53 (2007) 319.

[4] D. W. Breck, Zeolitic Molecular Sieves: structure, chemistry and use, Wiley, N. York, EUA (1973).

[5] C. S. Cundy, P. A. Cox, Chem. Rev. 103 (2003) 663.

[6] Y. Marui, M. Matsuoka, J. Chem. Eng. Jap. 37 (2004) 685.

[7] R. M. Barrer, Zeolites and clay minerals as sorbents and molecular sieves, Academic Press, N. York, EUA (1978).

[8] H. Yamada, S. Yokoyama, Y. Watanabe, H. Uno, K. Tamura, Sci. Techn. Adv. Mater. 6 (2005) 394.

[9] A. Gualtiere, P. Norby, G. Artioli, J. Hanson, Phys. Chem. Minerals 24 (1996) 191.

[10] S. Chandrasekhar, P. Raghavan, G. Sebastian, A. D. Demodaram, Appl. Clay Sci. 12 (1997) 221.

[11] W. Kim, Q. Zhang, F. Saito, J. Chem. Eng. Jap. 33 (2000) 217.

[12] M. Alkan, C. Hopa, Z. Yilmaz, H. Güler, Microporous Mesoporous Mater. 86 (2005) 176.

[13] A. A. C. Braga, N. H. Morgon, Quim. Nova 30 (2007) 178.

[14] G. Engelhardt, J. Felsche, P. Sieger, J. Am. Chem. Soc. 114 (1992) 1173.

[15] S. H. Kim, M. Park, Y. J. Son, H. J. Lee, G. C. Jeong, M. N. Bae, W. T. Limc, Bull. Korean Chem. Soc. 28 (2007) 567.

[16] M. Guisnet, F. R. Ribeiro, "Zeólitos. Um Nanomundo ao Serviço da Catálise", Fundação Calouste Gulbenkian, (2004).

[17] C. Kosanovic, B. Subotic, I. Smit, Thermochim. Acta 317 (1998) 25.

[18] J.A. Rabo, Zeolite Chemistry and Catalysis, Am. Chem.
Soc. Washington, EUA (1976)

[19] M. A. Subramanian, D. R. Corbin, R. D. Farlee, Mater. Res. Bull. 21 (1986) 1525.

[20] F. R. Ribeiro, A. E. Rodrigues, L. D. Rollmann, C. Naccache, Zeolites: Science and Technology, Martinus Nijhoff Publ. (1984).

[21] S. M. Auerbach, K. A. Carrado, P. K. Dutta, Handbook of Zeolite Science and Technology, Marcel Dekker, N. York, EUA (2003).

[22] A. A. B. Maia, "Síntese da zeólita A utilizando como precursor um rejeito de beneficiamento de caulim da Amazônia: aplicação como adsorvente", Diss. Mestrado Eng. Quím., Universidade Federal do Pará, Belém, PA (2007).

[23] B. S. Carneiro, R. S. Angélica, T. Scheller, E. A. S. de Castro, R. F. Neves, Cerâmica 49 (2003) 237.

[24] C. Klein, Mineral Science, John Wiley \& Sons, Inc., N. York, EUA (2002).

[25] H. Scheneider, K. Okada, J. A. Pask, Mullite and Mullite Ceramics, John Wiley and Sons, Inglaterra (1994).

[26] H. J. Rösler, Lerbuch der Mineralogie. Deutsche Verlag fuer Grundstoffindustrie, Leipzig, Alemanha (1991).

[27] S. M. P. Flores, “Aproveitamento do rejeito de caulim na produção de alumina para cerâmica e sílica de baixa granulometria“", Tese Doutorado em Geologia e Geoquímica, Universidade Federal do Pará, Belém, PA (2000).

[28] M. S. Barata, D. C. C. Dal Molin, Ambiente Construído 2, 1 (2002) 69.

[29] E. Saldanha, "Síntese e caracterização da analcima a partir de rejeito de caulim e aplicação como adsorvente", Diss. Mestrado Eng. Quím., Universidade Federal do Pará, Belém, PA (2006).

(Rec. 21/12/2007, Rev. 14/03/2008, Ac.04/04/2008) 